ANUARIO DE Estudios MEdIEVALES 44/1, enero-junio de 2014, pp. 277-308

ISSN 0066-5061

doi:10.3989/aem.2014.44.1.09

\title{
UN MONESTIR A LA CRUÏLLA. ELS INVENTARIS DE SAGRISTIA DEL MONESTIR DE SANT ANTONI I SANTA CLARA DE BARCELONA $(1389-1461)^{1}$
}

\author{
A NUNNERY AT THE CROSSROADS. \\ THE SACRISTY INVENTORIES OF THE MONASTERY OF \\ SANT ANTONI AND SANTA CLARA IN BARCELONA (1389-1461)
}

NÚRIA JORNET BENITO

Centre de recerca de dones Duoda - Universitat de Barcelona

Dedico aquest estudi a la historiadora M. Llü̈sa Orriols, morta el gener del 2011, companya en l'organització del fons arxivístic del monestir de Sant Benet de Montserrat i que féu unes primeres transcripcions de la sèrie documental dels inventaris (de convent $i$ de sagristia).

Resum: En el present article es posa al descobert la riquesa com a font històrica de primer ordre dels inventaris de sagristia del monestir de Sant Antoni i Santa Clara de Barcelona, primera comunitat de l'orde de Santa Clara en terres catalanes. L'estudi ens acosta a les particularitats d'aquesta sèrie documental en el seu fons arxivístic, la seva autoria (el càrrec de sagristana), així com a les principals tipologies de béns inventariats $i$ descrits (parament $i$ vestimenta litúrgica, orfebreria, obres d'art, llibres...). El conjunt permet donar una imatge rica de la cultura monàstica femenina, en l'acompanyament de la litúrgia, en la imatgeria sagrada, en la cultura escrita. Entre els resultats, sobresurt, la concepció funcional, curosa i detallada que la comunitat de germanes féu de cada peça, a l'hora de marcar el temps i el calendari litúrgic, com també a l'hora de gestionar i viure el dins/fora, la relació amb l'exterior.

\begin{abstract}
The Monastery of Santa Clara and San Antonio in Barcelona was the first community of the Order of St. Clare in Catalonia. The present article reveals the wealth of its sacristy inventories as first-class historical sources. The study illustrates the special characteristics of the series of documents in the monastery's archives: its authorship (by female sacristans) as well as the main types of items inventoried and described (liturgical clothing and ornaments, jewelry, works of art, books ...). The ensemble provides a rich perspective on female monastic culture with regard to its involvement in liturgy, sacred imagery and written culture. One of the outstanding results is an appreciation of the careful and detailed functional design applied by the community of nuns to each item, to keep track of time and the liturgical calendar, as well as to manage and live their relationship with the outside world.
\end{abstract}

${ }^{1} \mathrm{ADB}=$ Arxiu Diocesà de Barcelona; AMSBM/MSCB = Arxiu del Monestir de Sant Benet de Montserrat /Monestir de Santa Clara de Barcelona; DCVB = Diccionari català-valenciàbalear. 
Paraules claus: inventaris de sagrista; orde de Santa Clara; ornaments litúrgics; llibres.
Keywords: sacristy inventories; order of Saint Clare; liturgical ornaments; books.

\section{SUMARI}

1. Els inventaris de sagristia.- 2. La sagristana.- 3. La vestimenta litúrgica.- 4. Els paraments litúrgics.- 5. L'orfebreria.- 6. Les joies i altres ornaments per a la imatgeria sagrada.- 7. Les referències a la disposició de les peces i a l'espai monàstic.- 8 . Els usos de les peces inventariades.- 9. Els llibres.- 10. Conclusions.- 11. Bibliografia citada.

El monestir de Sant Antoni i Santa Clara de Barcelona fou la primera comunitat de l'orde de Santa Clara fundada en terres catalanes a la dècada del 1230, situant-se al costat d'altres monestirs hispans capdavanters en l'establiment de les germanes del segon orde franciscà -Pamplona, Burgos, Saragossa, Zamora i Salamanca. La seva particular història, tenyida per la llegenda fundacional que la fa creada per la voluntat fundadora de Santa Clara -que hauria enviat dues familiars i deixebles en un viatge miraculós fins arribar a la costa barcelonina- permet, per una banda, analitzar l'establiment i creació d'un nucli d'espiritualitat femenina de previ perfil beguinal, pietós caritatiu, que ha estat tocat $\mathrm{i} / \mathrm{o}$ empès en un punt de la seva història pel missatge mendicant i en particular per la trajectòria de les comunitats nascudes al voltant de Santa Clara, que esdevindran les primeres damianites o pauperibus (també dominae) inclusis monasterii Barchinonensi de ordine sancti Damiani. D'altra banda, el seu canvi el 1513 a la família benedictina permet tancar un cicle, en una història de l'espiritualitat femenina de llarga durada, que ens duu a altres episodis significatius de tancament d'estructures i de reformes monàstiques empeses des del poder, eclesiàstic i monàrquic, i que culminaran en les disposicions del Concili de Trento ${ }^{2}$.

L'objectiu d'aquest text és posar al descobert una font històrica de gran riquesa, entreveure les seves possibilitats d'estudi, amb el desglossament de les peces i objectes que acull la sagristia o que controla la sagristana, en la seva materialitat i funcionalitat; com també donar entendre la ubicació d'aquesta tipologia documental en el context del fons arxivístic de la institució i en el marc del funcionament intern de la comunitat (qui escrivia i el seu rang en la comunitat, quan ho feia i amb quina estructura o model documental). Com a rerefons se'ns perfila un espai comunitari que es troba a la

\footnotetext{
${ }^{2}$ Vegeu N. Jornet, El monestir de Sant Antoni de Barcelona.
} 
frontera amb un espai més públic com és l'església monàstica -que pot també esdevenir parroquial en algun cas. En aquest sentit pot ser interessant veure com es realitza aquest vincle entre el fora i el dins, enllaçat a més amb les funcions de ritual sagrat que es preparen en aquest espai, i que pren la seva significació particular en la vivència, vivència de la clausura per part d'una comunitat femenina. Pot ser significatiu, encara, el fet que sigui també aquest espai un punt que prepara o anuncia el contacte amb l'estament eclesiàstic que durà a terme el culte i l'administració de sagraments (preveres beneficiats, predicador).

No es tracta, certament, d'una font documental desconeguda; i ja s'ha fet evident des de diferents disciplines la capacitat dels inventaris com a tals (no explícitament "de sagristia") a l'hora de donar compte dels béns, de tot tipus segons també la concreció i especificitat de cada tipus de document, inventari o memorial. Des de diferents àmbits historiogràfics s'ha ressaltat doncs la importància de la sèrie, ben present als fons monàstics-eclesiàstics d'altra banda: la seva riquesa com a font inestimable per a recerques de cultura escrita (història del llibre i de la lectura), d'història de l'art (paraments litúrgics, obres d'art), per al coneixement de la disposició interna d'un habitatge, per als usos litúrgics i de l'espai monàstic, de vida quotidiana, etc. No se'ns escapa que, sota el terme "inventari", aquestes diverses aproximacions, poden incloure ja la genèrica accepció d'inventari com a relació i descripció ordenada de béns amb finalitat administrativa, de control; ja més explícitament el concepte d'un inventari notarial, post mortem, elaborat pel notari; o, encara, l'inventari/catàleg de biblioteca que progressivament incorporaria elements més de control bibliogràfic ${ }^{3}$.

Aquesta anàlisi que proposem ens permet, per començar, donar una radiografia de la comunitat monàstica en un moment de plena consolidació en l'entorn espiritual, topogràfic, social i econòmic de la ciutat de Barcelona, entre les darreres dècades del segle XIV i la primera meitat del XV. Com hem pogut determinar en d'altres textos, les antigues damianites barcelonines són, en aquests moments, una comunitat plenament assentada en l'espai, amb propietats urbanes, ubicades majoritàriament a les zones de les "viles noves" i concretament a la zona de la Vila nova de la mar. La comunitat s'ha fet també un lloc en la xarxa devocional de la ciutat i del territori, tant per la triada santa de l'orde -Antoni de Pàdua, Clara, Francesc-, com per la fama de santedat i de devoció local envers les dues "santes fundadores", Agnès i Clara. A nivell comunitari, el monestir ha participat en la fundació de les comunitats de Santa

${ }^{3}$ Una bona i recent síntesi, des del punt de vista de la història del llibre i de la biblioteconomia, a: C. Rodríguez Parada, Los catálogos e inventarios. 
Clara de Castelló d'Empúries, Santa Clara de Vilafranca, i a la mateixa ciutat de Barcelona, ha proporcionat el nucli primer de germanes per al monestir, de fundació reial, de Santa Maria de Pedralbes ${ }^{4}$.

\section{ELS INVENTARIS DE SAGRISTIA}

L'inventari és un instrument diplomàtic i jurídic de caràcter descriptiu i identificatiu a través del qual s'enumeren i descriuen ordenadament, a vegades segons uns criteris no massa clars o precisos, els béns, objectes, joies, documents i llibres, finques, etc. d'una persona o entitat. En uns casos obeeix a alguna norma preestablerta que el crea, com quan coincidia amb el tancament d'un càrrec o ofici o amb l'inici d'un mandat; en d'altres casos és conseqüència d'un acte dispositiu de l'autoritat que n'ordena la seva realització pel que fa al temps, lloc, manera, coses a inventariar. En el fons monàstic de Sant Antoni i Santa Clara de Barcelona, es conserven inventaris generals de convent, que coincideixen amb l'inici del mandat de l'abadessa ${ }^{5}, i$ inventaris vinculats a oficis comunitaris que han de tancar la seva gestió amb el memorial final del seu ofici. Podem trobar, encara, inventaris generals fets amb motiu de la presència del visitador al convent ${ }^{6}$. De fet els inventaris són una de les sèries més antigues, en paper i en format quadern -en front dels documents solts, en pergamí- que poden fer-se obligatoris o aparèixer en els capítols i constitucions d'alguns ordes monàstics i en els concilis generals i Constitucions papals, abans pròpiament de la reglamentació del Concili de Trento en matèria de producció documental i creació d'arxius ${ }^{7}$.

La sèrie documental d'inventaris de sagristia que ha conservat el fons de Santa Clara de Barcelona (integrat al seu torn a l'actual Arxiu de

\footnotetext{
${ }^{4}$ Vegeu N. Jornet, El monestir de Sant Antoni de Barcelona.

${ }^{5}$ Exemple d'inventari que es fa en motiu de la presa de possessió de l'abadiat de l'abadessa: any 1358, sor Francesca de Torrevella. AMSB/MSCB, Inventaris, Plec 813, núm. 16. El primer inventari general de convent que conserva el monestir, de 1337-1338, és fruit de les Constitucions de Benet XII, que fan menció dels inventaris que s'hauran de prendre en l'interval de dos mesos després de l'elecció d'una nova abadessa: inventari de béns i pertinences del monestir, mobles i immobles, els seus principals ingressos així com "quines obligacions deu lo monestir o li és degut". D'aquest document se'n faran dues còpies, una amb segell de l'abadessa i l'altra del convent, se'n farà lectura en capítol i se'n farà trasllat al general o al ministre provincial. MSCB, Inventaris, Plec 813, núm. 21-22.

${ }^{6}$ Amb la visita del ministre franciscà es fa un inventari general, incloent-hi les rendes i el seu corresponent valor monetari. El document es tanca amb el segell del franciscà. AMSBM/ MSCB, Inventaris, Plec 813, núm. 20.

7 Per a l'estudi del desenvolupament d'una arxivística monàstica, vegeu: M.L. García Valverde, Legislación archivística monacal.
} 
Sant Benet de Montserrat ${ }^{8}$ ) conté per a l'època medieval i l'etapa clarissa del cenobi onze unitats, amb un arc cronològic que va del 1389 al $1461^{9}$. Amb anterioritat al 1389 els inventaris generals de convent consignen les peces i els béns existents en l'espai de la sagristia o gestionats per la sagristana. A partir d'aquesta data es configura doncs una sèrie específica, de sagristia, separada del convent, com també apareixen al fons monàstic altres inventaris específics (cuina, procuració, infermeria) relacionats amb d'altres oficis o càrrecs (refetorera, capitolera, sagristana, cellerera).

Sobre l'estructura diplomàtica, tots els inventaris de sagristia analitzats s'inicien amb una invocació divina, excepció feta dels tres darrers (1454, 1457, 1461): En nom de Déu (1389), En nom de Déu sia e de madona Santa Maria (1406), En nom de Déu sia he de madona Santa Maria e de la Verge madona Santa Clara e de tots los Sants e les Santes del paradís. Amén (1410), En nom de Déu sia e de la Verga mare de Déu madona Santa Maria e de la Verga madona Santa Clara mare nostra (1421), IHS. En nom de Déu sia e madona Sancta Maria e madona Sancta Clara e de tots los Sancts de peradís (1433), En nom de Déu sia e de madona Santa Maria e de madona Santa Clara e de tots los Sants de paradís (1437) -en catalào In nomine Domini et beate Marie matris eius Sancteque Clare virginis Barchinone (1419) -en llatí. Mentre que els més moderns, en la cronologia analitzada, s'encapçalen directament pel nom de la tipologia documental: Enventari donat per mi, sor Aldonça Carreras, de les robes de la Segrestia en l'any MCCCCLVII (1437). Destaca l'inventari de sagristia d'Elionor de Rajadell que incorpora, a més a més, a l'inici del document, la frase: $O$ Vera Crux digna lignum super omnia ligna me tibi consigna me moriar morte maligna. Pel que fa als aspectes gràfics i formals, tots, a excepció dels dos primers i més antics, incorporen alguna caplletra a l'inici, en la invocació de la primera plana, i/o al llarg del text; en d'altres casos, es ressalten també les majúscules.

\footnotetext{
8 Vegeu Servei d'Arxius de la Federació Catalana de Monges Benedictines: http://www. federaciobenedictines.cat/wordpress/servei-arxiu/ [consulta: 30/09/2013]; i Guia de l'Arxiu de Sant Benet de Montserrat: http://www.benedictinescat.com/montserrat/htmlfotos/Arxiu.html [consulta: 30/09/2013].

9 1389, Eulàlia Despuig (AMSBM/MSCB, Inventaris, vol. 31, núm. 2); 1406, Marió Brulla (vol. 31, núm. 3); 1410, Eulàlia Bohigues (vol. 31, núm. 4); 1419, Eulàlia Esglésies (vol. 31 , núm. 5); 1421, Caterina Compta (vol. 31, núm. 6); 1433, Isabel de Gualbes (vol. 31, núm. 7); 1437, Elionor de Rajadell (vol. 31, núm. 8); 1454, Aldonça Carreras (vol. 31, núm. 9); 1457, Aldonça Carreras (vol. 31, núm. 9); 1457, Aldonça Carreras (núm. 12); 1461, Aldonça de Montcada (núm. 11). Manquen d'aquesta etapa clarissa del cenobi, els inventaris de sagristia de 1385, 1400 i 1403, esmenats i fets servir per la germana Dorotea Sarrovira entre 1632 i 1637 en les notes autògrafes sobre les dues "santes fundadores", i que es conserven a l'expedient de l'Arxiu Diocesà de Barcelona (vegeu nota 14). La sèrie continua en l'etapa benedictina del cenobi, a partir de 1513 .
} 
Des del començament, l'inventari reflecteix una ordenació real força precisa i ordenada, que situa els béns descrits en mobles (armaris) i calaixos i formant conjunts -coixins junts, pal-lis junts, frontals junts-i peces més petites com ara cofres i capses. És probablement l'inventari signat per Elionor de Rajadell, el 1437, el que presenta una millor estructuració del contingut, com també major precisió i detall en la seva descripció; i marca un tall, en la disposició i descripció, que seguiran les succesores en l'ofici i gestió de la sagristia.

\section{LA SAGRISTANA}

La sagristana era la monja encarregada de tot allò que es refereix al culte, la cura de l'església i cor de les monges, tenint al seu càrrec les robes $\mathrm{i}$ joies de la sagristia, els ornaments i paraments litúrgics, els llibres litúrgics o els més relacionats amb el culte; també podia encarregar-se del control dels bacins o caixes de les almoines donades pels fidels que assisteixen als oficis, si bé progressivament es perfilaria a la comunitat el càrrec de bacinera, $\mathrm{i}$ ja en època moderna, el de capitolera, que s'encarregava de la sala del Capítol on hi havia parat un altar, i el de sagristana de cor. Al monestir de Sant Antoni veiem la sagristana dedicada al culte especial a les santes (Agnès i Clara) o d'altres festivitats solemnes o majors. Ha d'escombrar el cor, vestir Nostra Senyora; probablement al seu càrrec estava també la preparació de l'aigua de roses amb què es perfumava l'església, el cor i la roba litúrgica; ha de tenir cura de parar l'altar del cor i posar-hi la crossa (el bàcul abacial) de plata en el ritual de confirmació de l'abadessa i presa de possessió. Té compte de pagar igualment al capellà o capellans de la casa. Si bé l'arxiver Sebastià Roger el descriu com un ofici "de vida", en la documentació sembla perfilar-se una durada de dos anys ${ }^{10}$.

La sagristana genera des de finals segle XIV documentació pròpia. A part de l'inventari o relació de pertinences relacionades amb el seu ofici, pot també ser autora de llibres de comptes generals que anoten les entrades (per exemple les ofertes o ofrenes per contribuir al culte o els ingressos per fundacions adventícies, aniversaris i sufragis) o els ingressos que li corres-

\footnotetext{
${ }^{10}$ Dades extretes dels dos manuals que redacta l'arxiver Sebastià Roger a la dècada del 1590 quan entra al monestir per organitzar l'arxiu monàstic: AMSBM/MSCB, Llibre dels càrrechs $i$ oficis del present monestir de Santa Clara, (1598), Manuals, núm. 743, f. 32. Llibre d'atorgacions, professions i òbits del monestir de Santa Clara (1598), Manuals, núm. 739. Per veure el paper i la importància d'aquest escrivent, Sebastià Roger, que intervé al fons monàstic a la dècada del 1590, organitzant la documentació, establint un servei d'arxiu i nomenant les primeres arxiveres, vegeu N. Jornet, Memoria, historia y archivo.
} 
ponen i que rep de mans de les tresoreres o dispenseres (en la comunitat de Sant Antoni també arxiveres); i les despeses (entre d'altres, la dels revestits o vestidures sacerdotals, la de cera, o la de les empaliades, el guarniment amb damassos, teles i per festivitats destacades com per Santa Clara i per Sant Llorenç). Segons la importància de l'ofici o al fet que estigués dotat amb les rendes específiques d'alguns béns, podem trobar encara en alguns fons monàstics d'altres llibres relacionats amb aquest ofici, com ara llevadors de rendes i capbreus.

És sens dubte un ofici important, present en tota comunitat i traduït de ben antic, com dèiem, en el fons arxivístic. En els documents analitzats, els noms d'Eulàlia Despuig, Marió Brulla, Eulàlia Bohigues, Eulàlia Esglésies, Caterina Compta, dels primers inventaris, són seguits pels d'Isabel de Gualbes, Elionor de Rajadell i Aldonça Carreras, al final de la nostra cronologia, que es tanca amb l'inventari d'Aldonça de Montcada de l'any 1461. Si bé ens mancaria un estudi complementari i més aprofundit de la personalitat i perfil social de cada sagristana, autora i redactora de cada document, en els casos que ens ocupen tenim dones procedents de l'alta aristocràcia (Aldonça de Montcada, que acompanya el seu inventari amb un escut, amb els besants dels Montcada, a la coberta) amb d'altres noms, com el de Marió Brulla, que procedirien possiblement d'un perfil més proper a la mà mitjana, artesana de la ciutat. En general però els inventaris analitzats destaquen per l'ús d'una escriptura de formes clares i cal-ligràfiques, fàcil de llegir. Podríem trobar alguna especificitat en la composició de les paraules, com per exemple, l'escriptura de Caterina Compta qui escriu el fonema " $k$ " amb la lletra "q" (qualaix, Quaterina, quapa, quamís, quorpus, quortines, quoronas, guarmesí...) i fa servir específicament termes com moniment (per monument) o plago (per plech). Més enllà d'aquests aspectes gràfics, es pot subratllar l'entrada de conceptes numèrics - suma o total de mantells de Nostre Senyor, o de porpres, entre d'altres- en l'inventari d'Isabel de Gualbes. I molt especialment, l'estructura ordenada, precisa, a l'hora de descriure els béns en l'inventari d'Elionor de Rajadell.

En l'inventari de sagristia, la sagristana presenta i dirigeix la relació de pertinences i béns vinculats al seu ofici a l'abadessa, autoritat visible: En nom de Déu. Sia memòria que jo sor Eulàlia Despuig fas a vós reverent madona l'abadessa (1389). És interessant anotar també els termes que la germana utilitza a l'inici del document i que al-ludeixen a la funció de memòria, memorial, remembrança i al control necessari efectuat per l'abadessa: fas a vós memòria de tota la roba de la çagristia... (1389); Remembransa sia a vós madona l'abadessa que jo sor Marió Brulla jaquesc en la sagristia... (1406); Remembransa sia a vós (...) les coses escrites en lo present inventari, lo qual vos lliure... (1419). El memorial 
s'efectuaria, en set dels onze documents analitzats, el darrer divendres del mes de maig ${ }^{11}$.

\section{LA VESTIMENTA LITÚRGICA}

Un primer gran bloc de béns descrits és la vestimenta litúrgica, ben present des de l'inici de la nostra cronologia. Són habituals les entrades genèriques de vestiment, amb el seu color (negre, verd, blanc, vermell...) o material (de sendat verd, de carmesí...), i sovint detallant el seu compliment:

I vestiment negre amb tot son compliment: una tala blanca i una tovallola negra, I capa negra amb fres; vestiments blancs amb tot son compliment de estoles, maniples, cues, amits, camis i III cordons de seda vermella.

Es perfila la vestimenta sacerdotal (casulla, estola, maniple, camis, capa, cinyell o cordó, dalmàtica, sobrepellís). I, com veurem, és molt habitual trobar referències a l'ús litúrgic o del calendari litúrgic del vestiment descrit.

Podem trobar vestiments més explícits, com el mantell de borell que té el confessor cont confessa las ditas dones nostres i el vestiment a obs del confessor, amb una tovallola i un sobrepal-li (1389); els sobrepellissos pels preveres (1410); I vestiment del confessor ab tot son compliment i I sobrepelís per son companyó (1410); el vestiment pel confessor quan entra dins (1419); els dos sobrepellissos petits per als framenors i, encara, els dotze mandils los quals servexen a l'altar de fora per los preveres (1437). Del 1437 és la primera referència als vestiments dels confrares de Sant Elm (la confraria més antiga documentada i que reflecteix el perfil social i l'entorn mariner en què es trobava l'antiga comunitat de damianites): una casulla verda brocada d'or, dues dalmàtiques verdes brocades d'or amb paraments de vellut vermell.

Les descripcions s'omplen progressivament de senyals o referències heràldiques: Sant Climent, Marquet, Cruïlles, Conques, Cervelló, Castells, Roure, Suelves..., són alguns dels noms referenciats, especialment en el parament litúrgic com ara els frontals, els pal-lis, els dossers i les porpres. Molt sovint en més d'una peça, conformant un conjunt (I porpra blanqua amb III senyals de Sent Climent e de Marquet, e un frontal en la dita manera matexa, 1461). Famílies com els de Sant Climent, Marquet i Cruilles, sabem que tenien una vinculació directa amb la comunitat essent dels primers noms de les

11 Trenquen aquesta norma els inventaris més moderns que ho fan també semblantment en divendres però del mes d'agost (1437, vol. 31, núm. 8); mes de març (1461, núm. 11). 
germanes que conviuran al clos monàstic ${ }^{12}$. En alguns casos es fa referència directa a la persona que va fer el llegat o deixa testamentària; per exemple, el dosser verd amb orla negra amb senyal de Goreya e de Mandoça, que féu la senyora de Goreya i present a l'inventari de sagristia des del 1433; o el mantell carmersí que ha donat la senyora Francina de Rajadell, que entra al repertori d'objectes el 1461. Documentat ja al primer inventari de 1389 és el llegat de Dona Blancha que inclou: una casulla de drap de seda vermella amb imatges, amb dues estoles i un maniple (és de dona Blancha); I drap d'aur per cobrí la tomba de dona Blancha, un missal, un estoig de corporals, un calze, una ara de jaspí, una creu d'argent i un dosser.

En bona part dels inventaris, els vestiments i els paraments litúrgics en general apareixen esmentats en "conjunts" o plecs (plachs, plegos). Per exemple: I plach de morts ab tot compliment de vestiments negras o VII plachs de vestiments de sendat verd (1406). Amb més precisió i detall en la seva composició: un pal-li, dues tovalloles, una de cotonina negra amb senyals reials i l'altra de sendat negre, dues cortines, dues tel-les (una que serveix per cobrir la tomba, l'altra per posar la Creu) i un drap negre, conformen un plech de mort negres (1410); en el seu destinatari: tres plechs de morts, la I pel qui diu la missa, l'altre pel diacha, l'altre plec per lo sotsdiacha (1437); un altre plec lo qual serveix al confessor, compliment hi a de ço qui necessari és per lo dit confessor (1437); o encara per al seu ús litúrgic: un plec gros que serveix en la Coresma per l'altar de defora, amb un pal-li barrat blanc, cinc draps, dues cortines flocades blanques, una casulla, estola i maniple blancs (1437). A mesura que avancem la cronologia, i especialment a partir de l'inventari d'Elionor de Rajadell, trobem que el plec incorpora també els draps per cobrir o per aplegar: una porpra ab lo camper vert brocade d'or ab frontal e floquedura blave, vermella e d'or folrat blau ab draps de li per a cobrir les dites robas (1437).

\section{ELS PARAMENTS LITÚRGICS}

Un segon gran àmbit de l'inventari el formen els paraments litúrgics (tèxtils). És aquesta una secció que s'amplia i s'enriqueix, i on els ítems són també cada cop més precisos en la descripció i enumeració, tant per als detalls del material i composició de les peces com pels seus usos litúrgics. Destaquen els pal-lis de diferents colors (d'or, blanc, negre), amb senyals (d'Empúries,

${ }_{12}$ Els noms de Ramona Marquet, Beatriu de Crü̈lles, Margarida de Sant Climent i Sança de Conques apareixen en la documentació del primer segle d'existència de la comunitat. Vegeu Jornet, El monestir de Sant Antoni de Barcelona, pp. 205 i ss. 
Castells, Roure, Cervelló), amb imatges (un pal·li de Sant Antoni blau amb imatge de Santa Clara sembrat d'estrelles d'or, el 1389; dos pal-lis d'or amb figures d'àngels i un pal·li d'or amb Anunciació, el 1406; un pal·li de drap d'or amb la imatge de madona Santa Maria, el 1419; un pal-li de satí ras estelat d'or amb la imatge de Santa Clara al mig, el 1433; un pal-li de vellut blau $a b$ els parpolaments perfilats d'or ab ymatge de Sant Francesch, al mitx ab senyals de Cortey, el 1461). Pal-lis de teles específiques (de taurí, de vellut blau, de fustany, de seda escarlata). Com també per a usos litúrgics o ubicacions específiques: I pali per les octavas, I altre per los disaptes de septuagèsima, un pali negre brodat d'or que solie star tot dia en l'altar (1410), I pali de fustany e I cortineta blancha qui solie servir en l'altar de madona Santa Maria (1406); I frontal de xemellot blau qui stava en l'altar de dintre (1410); o I pali blanch per l'altar de Sant Anthoni (1389).

Els frontals apareixen molt sovint al costat dels pal-lis, formant conjunts d'una mateixa procedència o benefactor (un pali blanch ab randa a cade cap ab un frontal ab tres creus negres ab flocadura blanque e negre, lo qual pali e frontal servex a l'altar de defora de madona Santa Maria, el 1454). Són especialment paraments amb imatges i senyals heràldiques. Ja al primer inventari, del 1389, consten: dotze frontals, set amb imatges, cinc amb senyals; i es detallen els frontals amb imatges de Sant Antoni, els Apòstols, les Verges, els Àngels. A partir de 1410 són constants i nombroses la presència de les perles. D'aquesta data, per exemple, és el frontal blau amb figures d'or en lo qual és l'abeniment del món en lo qual ha CXXX unes perles (el 1433 es diu que té ja cent quaranta-nou perles). L'any 1461 consta hun frontall en què són los Set Gotxs de la Verga Maria e la Passió ab CXXXXVIII perles (que el 1437 en tenia cent trenta-nou). Com en el cas del pal-lis, els inventaris poden detallar els usos litúrgics dels frontals ( 1 frontal negre brodat d'or per les mortes) i precisar-ne la ubicació (un frontal de xamellot blau qui estava en l'altar de dintre). Al darrer inventari de l'any 1461 es dóna la suma de setze frontals.

Els mantells descriuen habitualment peces tèxtils destinades a ornar i cobrir imatges. El 1406 es documenta un mantell de vellut vermell amb teixells que solia ser per a la imatge de madona Santa Maria de defora. I és a així que es defineixen com a mantells de Nostre Senyor o de la Verge Maria. Els de Nostre Senyor són tres, el 1389 (dos verds, un blau amb estrelles d'or) i ja són cinc el 1437 (I de carmesí brocat d'or e vellutat ab fres e entorn dues magranetas d'argent deurades ab senglas perlas al cap; I de vallut vermell ab brots d'or; I altre de cetí blau stelat; I altre negra brocat d'or i blau; I altre de cendat barrat d'or). Els de la Verge Maria són quatre mantells, el 1421 (un de valut vermell brodat d'aur folrat de tela blanque e un de blau de velut sembrat de astelas e de saygs d'aur e un de velut vermell qui és de la ymatge de pedra petita). Agafa presència progressivament en la documentació el terme 
porpra, parament tèxtil especialment decorat amb senyals heràldiques, amb presència als altars:

I porpra mesclada de blanch e de or qui servex a l'altar de Santa Maria Magdalena; I porpra e frontall de cotonina negra ab brots de or ab dues cortines negres qui servexan al nostro altar al die dels morts.

L'any 1461 es dóna la suma de vint porpres.

Tovalloles i eixugadors, draps i corporals, cortines i tapits, coixins, són d'altres elements tèxtils presents als inventaris. Tovalloles amb uns usos i espais diversos. L'any 1461 es precisen: sinch tovalloles qui serveixen al feristoll per dir la Capítola davant l'altar, dues ab botons d'ergent, totes són locades ab flocadura de vert, vermell, groch e blau; I tovallola blanqua encanyissada que servex al combregar de les monges en la yglesya. Per cobrir les creus, com es precisa a l'inventari de 1437: III tovalloles, la I és blancha de li brodada d'or, l'altra és de seda blancha e listade e tota d'or. Les dues altres són domesquinas, la I molt gran, l'altre poqueta, les quals servexen al Divendres Sant a cobrir la Vera Creu. Apareixen també des d'un començament els corporals, en tant que drap blanc que especialment es col·loca damunt 1'ara o altars on se celebra la missa per posar-hi el calze i l'hòstia. L'any 1433 es referencia per primera vegada l'estoig amb corporals, blau i d'or, juntament amb una ara de jaspi, que'ns donà la senyora reyna dona Yolant ${ }^{13}$.

Les cortines, com els corporals, se situen preferentment en els altars. El 1410 s'inventaria el plech de draps de l'altar de Sant Anthoni, format per: tres teles, un pal·li orbrat, dues cortines, un pal·li de fustany i una casulla. Des del primer inventari es documenten les cortines de l'altar de dins i el de fora: IIII cortines barrades de groc e de vermell per l'altar de fora e de dins (1421), II cortines negras, qui servexen al dia dels morts a l'altar nostro (1437); i el 1461 s'arriba a inventariar els dos bastons prims al cap de cascun bastó ha dues corriollates qui servexan a tenir les cortines al nostro altar de Coresma.

Els coixins tindran en la història i memòria de la comunitat un lloc important al considerar, a la primera dècada del segle XX amb l'inici del procés de beatificació, que els coixins de Santa Agnès correspondrien a la figura de la "santa" fundadora, Agnès de Peranda. Aquests inventaris, convenientment

13 Probablement es tracta de la reina Violant de Bar (1365-1431). El jaspi, com a pedra fina, fa pensar en els gustos refinats de la sobirana per les joies i guarniments per als vestits, els llibres de luxe, com també els rics contenidors -estoigs- que poden contenir teixits o relíquies. Una recent aproximació als gustos artístics d'aquesta reina en el marc de la promoció reial: R. Terés, Violant de Bar. 
identificats i senyalats a la portada ${ }^{14}$, esdevindran "proves" -del culte a l'abadessa- i s'integraran a la Causa de beatificació i confirmació del culte d'Agnès de Peranda i Clara de Janua ${ }^{15}$. A l'inventari de 1406 apareix per primera vegada el mantell i la gonella de Santa Agnès (al costat de la gonella de Sant Gerard), i significativament també al costat de: l'espasa de Sant Pau, les claus de Sant Pere i el coltell de Sant Bartomeu (a l'armari sota els calaixos de les porpres), i a prop del cap de Santa Eugènia (a l'armari de sobre els calaixos de les porpres). I a partir de l'inventari de 1437, ja solament consten els coixins de Santa Agnès. Veiem d'altra banda que els coixins (més enllà, com dèiem, de la significació o resignificació que en farà la comunitat lligada al culte dels dos cossos sants ${ }^{16}$, el d'Agnès i el de l'altra fundadora, Clara) se situen, en la disposició i en l'inventari, al costat d'altres relíquies. Els coixins, en genèric, es fan servir essencialment a l'hora d'adorar, pregar -com ara els dos coixins grans obrats de seda per adorar la creu el Divendres sant- o acompanyen algun element del tresor - una imatge, la de madona Santa Maria, o un llibre, el missal de fora. La presencia de coixins per los reials ${ }^{17}$, o els coixins pels ministres, fan pensar en un element decoratiu més funcional, relacionat amb les visites externes.

\section{L'ORFEBRERIA}

L'àmbit de l'orfebreria ocupa un lloc important en l'inventari. Parlem de creus de diferents materials (de llautó, de fust, d'argent amb esmalts, de cristall amb esmalts, creu d'argent daurada amb senyals del Rei de Sicília), de diverses tipologies (creu major, veracreu, creu de fora) i que apareix majoritàriament al costat d'altres elements: creu major amb la tovallola domesquina i el cordó verd i un vel de seda amb ros d'or (1410); una creu d'argent amb el seu estoig (1389); un peu de fust pintat per a la creu petita d'argent; veracreu amb una tovallola obrada, quatre bordons i un bastó per a la creu (1406); dues tovalloles per cobrir la creu (1410); dos coixins per la creu (1419); onze

${ }^{14}$ Anotacions en lletra manuscrita moderna a les portades o primers fulls dels inventaris del tipus: En fol. 5 dos coixins de Santa Agnès (1461), Es de Sancta Agnès en fol. 4 (1433); Parla de les santes, fol. 4 (1421).

${ }_{15}$ ADB, Beatificationis seu confirmationis cultus servis Dei Agneti de Perandae et Clara de Janua. 1912. Processus Beatificationis. Canonitationis, núm. 37 bis.

16 J.M. Masnou i Pratdesaba en la presentació i anàlisi de l'inventari de la sagristia de la Seu de Manresa de l'any 1425 anota també objectes lligats al culte dels Cossos Sants: J.M. Masnou, Inventari de la sagristia de la Seu de Manresa.

${ }^{17}$ El 1240 per privilegi papal es permetia l'entrada al monestir 3 cops l'any causa devotionis a la reina Violant juntament amb les seves filles, AMSBM/MSCB, Col·lecció de pergamins, núm. 254. 
vels de seda amb lletres d'or que serveix per cobrir la Creu (1437), una tela blanca de cotonina per adorar la creu de fora el Dijous sant (1437). Pel inventari de 1461 coneixem què hi havia a l'armari de la creu:

un bastiment de fust gros on stà la creu major, i és hi la dita creu d'argent daurada ab lo crucifix al mitx. Ítem, hi ha una tovellola de çeda ab listes blanques e blaves, verdes, vermelles ab flochs de or e de çeda verda. Ítem, un cordó de çeda ab botons verts e de or. Ítem dos claus d'argent ab los caps daurats per la dita creu. Ítem dues vanovetes qui stan la una sota la creu e l'altra de sobra. Ítem una creu petita d'argent blanqua ab hun crucifix al mitx e bax en la creu ha un tros de la Vera creu ab un cendat que stà enbolicada. Ítem hi ha un coxí brodat de moltes colors lo qual servex a posar la creu e hun peu de fust en què stà la dita creu, daurat e blau.

Formen també part d'aquest àmbit els canelobres (un de fust argentat, de tres poms, que serveixen al Dissabte de Pasqua); els bacins (dos bacins per a la unció), les canadelles ${ }^{18}$ (de cristall o vidre, d'argent i corall), els encensers (un encenser amb la barca); els brasers (el que conté les brases quan es dóna encens per les festes majors); els reliquiaris i les custòdies (una custòdia amb esmalts, amb dues cobertes de vellut folrades de seda i or en què està lo cors preciós de Jesucrist, una custòdia d'argent sobredaurada amb una creueta de perles amb fust de la Veracreu); els salpassers ${ }^{19}$ (un salpasser que serveix per dar la salpaça a les festes, altres de pintats per als diumenges i dos de blancs per tots els dies); les llànties (unes per les festes majors, d'altres, blanques, per a tots els dies); els calzes; les paus, portapaus o posts per la pau (una pau amb IIII posts e una tovallola negra ab flocadura blave que servex als diumenges a donar pau a les dones, o I pau d'ergent deurada amb lo crucifix al mirg amb Nostra Dona i Sent Johan, embolicade amb sendat blau).

\section{LES JOIES I ALTRES ORNAMENTS PER A LA IMATGERIA SAGRADA}

Hi ha una secció significativa que augmenta progressivament amb el temps que són les joies i altres peces que serveixen per ornar les imatges de l'església. L'inventari de 1437 parla concretament de les joies de la Verge Maria i enumera: una gandalla ${ }^{20}$ de canons d'or amb la clenxa de veta violada i sembrada

18 DCBV: Cadascun dels dos pitxerets o ampolletes amb broc que serveixen per ministrar el vi i l'aigua per a l'oblació en la missa.

19 DCBV: Objecte que serveix per a fer les aspersions d'aigua beneita.

20 DCBV: Lligadura de malla de seda o d'altre teixit fi, i a vegades de fil d'or, amb què antigament portaven recollits els cabells les dones. 
de perles petites; un cinyell amb llaçada blau i vermell; unes polseres de fil d'or; una clenxa de llana de nacre, que serveix per al cabells de la Mare de Déu; un partidor $^{21}$ amb onze senyals d'argent daurats, dotze perles i quatre pedres, dues de blaves i dues de vermelles; unes filosetes de perles amb canons d'argent daurats (els encastaments són de set perles, els canons són sis i hi ha catorze magranetes d'argent daurades); unes arracades amb deu senyals d'argent cadascuna; un collar de perles amb tretze canonets daurats i fulletes i pedres. Apareixen també les diademes o garlandes, destinades igualment a les imatges de madona Santa Maria i de Nostre Senyor: unes, de fulla d'or amb pedres i perles (una garlanda de fulla d'or amb sis pedres blaves i cinc de vermelles, setanta-quatre perles grosses, any 1410); altres, de seda blanca (una d'esses, l'altra de rosetes amb pedres blaves, any 1410), de perles i de paternostres. I es parla així mateix de les corones, les orelleres, els pitrals ${ }^{22} \mathrm{o}$ davanteres (un pitral d'ergent deurat, qui servex als pits de la Mare de Déu e una agulla d'ergent per refermar lo dit pitral), els collars i les polseres, els rams de perles. Completen aquesta imatgeria: les cabelleres de cànem, la barba i el barret per a la imatge de Nostre Senyor. En l'inventari de 1422 es comptaven nou cabelleres, set barbes i dinou diademes.

S'esmenten en la nostra cronologia algunes escultures: imatges en pedra de Santa Maria (en un dels ítems, amb dues diademes, i un altre, amb el seu coixí). La resta és especialment amb metall i pedreria (un post d'argent amb la imatge de Sant Miquel, amb vint-i-una pedres fines i vuitanta perles, el 1437). Pel que fa a la presència de retaules, l'inventari de 1461 concreta que es conserven a l'armari de l'orla e retaules: tres retaules, cadascun de dues peces; una caixa amb quatre cabirons (e un cabiró per lo mig en què és la imatge de la Verge Maria); una caixa amb quatre posts de l'orla daurades; una caixa amb quatre àngels de fust daurats i una imatge de Nostre Senyor daurada, sis lliris daurats i sis d'argentats, sis roses daurades i vint-i-quatre peus de fust daurats i argentats. I, a part, s'esmenta i un retaule amb quatre posts que serveixen a la festa dels Apòstols. A la casa dels òrguens hi ha el bastiment de la casa de Nostre Senyor que són trenta-tres peces, entre grans i petites. Cal pensar aquí molt possiblement en un conjunt de peces destinades a conjunts, bastiments temporals que es construeixen en determinats moments del calendari litúrgic, normalment en les festes grans i majors de la comunitat (el 1406 es menciona un rerataula per les festes majors que són tres peces). Com dèiem en començar, consta que la sagristana de Sant Antoni s'encarregava també de les empaliades (conjunt de domassos, teles i altres ornaments amb què s'empalia un edifici), bastits especialment per les festivitats de Sant Llorenç i Santa Clara.

${ }^{21}$ DCBV: Pinta o agulla per a fer la clenxa o ratlla dels cabells.

22 DCBV: Joiell que es portava sobre el pit. 


\section{LES REFERÈNCIES A LA DISPOSICIÓ DE LES PECES I A L'ESPAI MONÀSTIC}

Més enllà de la tipologia de béns descrits, els inventaris de sagristia poden donar altres elements d'interès en relació a la disposició i l'ordenació de les peces en mobiliaris o receptables diversos (armaris, calaixos, cofres i capses). Les referències a mobiliari guanyen en precisió i detall en dates més avançades, i donen compte d'una ordenació en l'espai acurada, que acompanya també una major classificació de les peces segons tipologies: lo terç calax qui és dels mantells de la Mare de Déu, o lo quint calax de lo sobrealtar i les tovalloles, l'armari dels bordons; l'armari dels calces; l'armari del faristol de les cantores; el terç armari qui és tanidor de camis, sobrepalliços e altres cosas. O fins i tot el detall en el color: calax dels vestiments negres, calax dels vestiments blanchs, calax dels vestiments vermells. Com també augmenten la disposició dels objectes en capses o caixes, de tots mides i colors que, per exemple, a l'inventari de 1406, es descriuen en detall per emmagatzemar i conservar les joies i l'orfebreria: un ram de perles amb una flor al cap amb nou perles grosses (dins una capsa), orelleres de seda amb pedres vermelles i quatre cors d'argent daurats (en una capsa llarga); dues davanteres per la imatge de fora (en una capsa rodona); dos parells de polseres de seda (en una capsa vermella). Fins i tot es precisa una capsa vermella i groga foradada pel mig que serveix a la Quaresma per tenir la corona de la Mare de Déu.

Apareixen, en l'enumeració dels béns, referències a l'espai o l'habitatge monàstic, on se situen cofres i caixes. És així que a l'inventari de 1437 apareix el cofre del Capítol $^{23}$, el cofre que és prop la porta ${ }^{24}$, la caixa dels tapits que és prop de la porta ${ }^{25}$, la caixa que és sota la volta ${ }^{26}$, l'armari de la volta ${ }^{27}$. S'esmenta encara, la casa de les escombres, on el 1421 s'assenyalen: una cenalla on hi ha vint-i-nou poms de fust pintats, sis pinyes, un foguer, dos salpassers pintats pels diumenges i un de blanc per cada dia, un bastó per espolsar el bancat millor, una senalla amb senyal de Sant Antoni per posar-hi les escombraries i un salpasser verd de coure. Recordem que entre les atribucions de la

23 Amb cinc bancals amb figures, cinc cortines blanques encanyissades per la Quaresma, cinc estores per estorar l'església.

${ }^{24}$ Amb un custòdia d'argent daurada amb una creueta que està sobre la custòdia amb perles amb un tros de la veracreu; un creu d'argent daurada amb el senyals del rei de Sicília; la corona de la Mare de Déu d'argent daurada amb pedres i perles d'argent i un ram d'argent de flors i la corona de Nostre Senyor d'argent daurada amb pedres i perles d'argent, en sengles capses; uns paternostres d'argent daurats en una capsa petita llarga).

${ }_{25}$ Amb cinc cobertors de seda, quatre tapits, quatre capitells i un bancal que serveix al banc de les cantores.

${ }^{26}$ Amb cent quarante-set neules, entre pintades i blanques; nou cabelleres, set barbes i dinou diademes.

27 Amb dos imatges de pedra de Santa Maria. 
sagristana es troba escombrar el cor. I es parla finalment de la casa dels orgues (on hi el bastiment ja esmentat de la cambra de Jesucrist i el de l'esquella; dos tapits que serveixen per les festes i un bancal per les cantores).

Les referències espaials arriben a detallar alguns aspectes de l'església. Així, en l'inventari de 1437 es descriu la imatge de la Verge Maria amb una corona d'argent daurada i ligada ab tot son compliment, ço són arrecades de perles d'ergent e de pedras, lo collar és de pedres blaves i blanchas; té en la mà un ram de seda de moltas colors ab el peu vert i daurat. I la de Nostre Senyor, que duu un barret al cap brocat d'or ab brots de perlas e paternostros de coral. S'esmenten també dos armaris a la pared: un amb la Vera Creu, en l'altre el reliquiari; un altre armari que està als peus de la Verge, on hi ha una caixeta de fust coberta de llautó i llaunes de ferro amb relíquies, i una altra caixeta de vori en què hi ha dos barralets d'oli infirmorum (1437). Encara dins l'església, es descriu el faristol de les cantores, amb dos armaris. Al primer: els calzes millors (són quatre, tres de daurats i un tot blanc), una albadina de cuiro blanc on hi ha l'encens; una capsa blanca amb encens; tres claus que són tenidors del ciri del fas; un parell de bacines de llautó que serveixen per la provisió de les germanes i un llibre del confessor. Al segon: cinc calzes, tres de daurats i dos de blancs; un encenser d'argent, una barqueta d'argent amb cullera d'argent i el Datari (1437).

\section{ELS USOS DE LES PECES INVENTARIADES}

Certament, la descripció dels elements de l'inventari ja ens ha pogut donar compte dels usos dels objectes i paraments regits pel calendari litúrgic, presents en els rituals més significatius de les germanes: coixins per adorar la Creu i les imatges, vels per resar Madona, joiells i atuells -lliris, barbes, cabelleres, corones i diademes- que ornen la imatgeria de Nostre Senyor i de la Verge Maria, llençols i draps per lligar i embolicar la Mare de Déu. Es documenten també les ales (el 1406, quatre parells d'ales, dos parells de vermelles i un parell de daurades i l'altre argentades) que es poden integrar a aquesta escenografia de la imatgeria sagrada que es dibuixa a través dels inventaris. Una escena que pot quedar completada amb la presència, ja al principi de la nostra cronologia, de les neules, que servien, en una costum ben antiga, per ornar les esglésies (el 1406 s'enumeren cent seixanta-set neules dobles i blanques i disset de pintades) ${ }^{28}$.

${ }^{28}$ DCBV: Per l'advent, a Mallorca és costum de penjar a les llànties i salomons de l'església tantes neules com setmanes manquen per a la quaresma. A l'Empordà, en la vigília de Nadal anaven a l'església els joves del poble presidits pels obrers o pabordes de Sant Joan Baptista, lligaven a la capella d'aquest sant una partida de fils passats d'un costat a l'altre fent com una 
Els inventaris són curosos a l'hora de descriure conjunts d'elements que marquen un ús especial, relacionat amb aquest temps o ritual litúrgic. Per exemple, la Quaresma: I plech gros lo qual servex en la Coresma per lo nostro altar dins, (i que comprèn una cortina gran flocada que serveix per cobrir l'altar, amb bagues i anells; un llençol de dues teles que serveix per embolicar la Mare de Déu de Quaresma; un llençol amb dues bagues que serveix per lligar la Mare de Déu de Nadal fins al Tres Reis d'Orient -aquest llençol es posa de clau a clau sobre el tabernacle; dues cortines barrades que serveixen al costat de l'altar de dins i una tela blanca; una camisa que està sobre el tabernacle de la Mare de Déu; una coberta blanca barrada amb flocadura blava que serveix per cobrir el cimbori amb un tros de drap ensemps; un pal-li blanc amb randa a cada cap). Un plec gros lo qual serveix en la Coresma per l'altar de defora (i que té un pal-li barrat blanc, cinc draps, dues cortines flocades blanques, casulla, estola i maniple blanques, estola amb flocadura negra, maniple blanca, verda i vermella). Per Quaresma s'anota igualment: el monument ${ }^{29}$ en què està lo Corpus lo dia del Dijous Sant de fora; la mostra de la Veracreu Divendres Sant sota un papalló30; els ciris i el bastó per al fas ${ }^{31}$ de Dimecres, Dijous i Divendres Sant, a matines; i el tenidor de fust argentat amb tres poms foradats que serveixen el Dissabte Sant quan beneeixen les candeles.

Apareixen també conjunts de peces ben integrades en la litúrgia quotidiana. Per exemple, el que s'enumera que hi ha dins una capsa gran i blanca i que són les coses necessàries per lo combregar de les sors: sis tovalloles totes blanques i molt llargues; una tovallola petita blanca flocada i randada que serveix per prendre el calze; una tovallola brodada de molts colors que serveix a la finestreta per combregar; dues tovalloles de drap de seda; una tovalloleta de seda amb pinyes verdes i d'or que serveix sobre la tauleta on es posa els calzes; un vel de seda negra amb llistes d'or i vermelles que serveix al confessor quan dóna la comunió a les sors. Ja s'han esmentat els vestiments i els paraments tèxtils integrats en l'ofici: la capa vermella amb fres d'or que serveix per les esperges (aspersió amb aigua beneita); la porpra negra amb imatge de Nostre senyor que es posa el dia que tenguan Aleluya, Aleluya, Aleluya ${ }^{32}$; els

mena de sostre, i en aquests fils enfilaven una multitud de neules, que hi romanien penjades fins després dels Reis. Les neules són també un ornament molt usat en el sostre dels betlems o pessebres de Mallorca.

${ }^{29}$ DCBV: Altar més o menys adornat que es disposa en les esglésies per a exposar-hi durant el Dijous i Divendres Sant l'urna que representa el sepulcre de Jesucrist.

${ }^{30}$ DCBV: Tenda de campanya de forma cònica.

${ }^{31}$ DCBV: Les matines del dimecres, dijous i divendres sant es té exposat un triangle de ciris $i$ es va apagant un ciri a la fi de cada versicle, fins a romandre tots apagats.

${ }^{32}$ DCBV: Mot d'alegria que l'Església canta principalment en el temps pascal, darrera les antífones. 
vestiments de sendat verd amb tot el seu compliment que serveixen al Dissabte Sant; o les tovalloles flocades amb flocadura de verd i vermell, i groc i blau, dues d'elles amb botons d'argent, que serveixen al faristol per llegir la Capítula davant l'altar.

Es perfila per tant tota una cultura visual complexa, la dels monestirs femenins medievals, que ha analitzat perfectament Jeffrey F. Hamburger, i on les peces, en aquest cas les que controla la sagristana, interactuen les unes amb les altres en un ampli teatre de la devoció, organitzades segons els patrons generals de la pietat i amb tota una perfomance litúrgica i paralitúrgica ${ }^{33}$-paralitúrgica, seguint l'historiador, en el sentit de propera o al costat de la litúrgia, de la missa de l'ofici diví. Objectes integrats també en una dimensió comunitària, compartits en funcions litúrgiques, commemoratives i devocionals ${ }^{34}$.

Amb aquesta precisa funcionalitat de cada objecte descobrim també que la comprensió de l'espai monàstic és inseparable de la del temps monàs$t_{i c}{ }^{35}$. Això és, en termes d'identitat monàstica, resulta tant o més important l'ús de l'espai, que la seva pròpia identitat física; un espai, com dèiem, limitat i marcat pels mateixos objectes o perquè s'hi realitzen activitats específiques marcades al seu temps per un ritual i una rutina diària. Seguint Columba Steward $^{36}$, en un programa d'establiment monàstic, l'organització material (espais, usos, funcionalitat dels objectes) és normalment més precisa i elaborada que en d'altres contextos perquè suposa sovint una duplicació d'espais per a servir la comunitat monàstica i els hostes seculars. I en aquest sentit parla d'una diferenciació funcional del temps i tasques conforme al calendari litúrgic, i d'una diferenciació ideològica de l'espai i el temps (atribuïnt certes qualitats als espais o moments) per renforçar els valors fonamentals de la vida monàstica ${ }^{37}$.

És en el marc d'aquesta interpretació que apareix als inventaris el joc del dins-fora, que anota perfectament la sagristana en el seu paper i en el punt d'intersecció que ocupa l'espai de la sagristia ${ }^{38}$. En el quadre monumental que representa el complex monàstic a principis del segle XVIII -i que conserva l'actual comunitat de Sant Benet de Montserrat- veiem efectivament com la sagristia se situa darrera mateix del presbiteri, i al costat de la sala del capítol, i molt a prop de la capella de les Santes ${ }^{39}$. Des del primer inventari de 1389

33 J.F. Hamburger, Nuns as artists, p. 20.

${ }^{34}$ Ibidem, pp. 51-52.

${ }^{35}$ G. Cantino Wataghin, Concluding Remarks, p. 364.

${ }^{36}$ C. Steward, Monastic space and time, pp. 43-51.

${ }^{37}$ Ibidem, p. 44.

${ }^{38}$ Blanca Garí ha analitzat l'espai del cor monàstic també com un espai de creuament, entre l'església i la clausura, que esdevé d'altra banda el cor de l'espai devocional femení, a B. Garí, The Sacred Space of Meditation.

${ }^{39}$ Probablement fou pintat entre 1708-1714 (abans per tant de la destrucció de l'edifici). 
es referencien uns sobrealtars per als altars de fora i el 1406, un missal de fora, una imatge de fora, o un tapit per l'església de fora per l'altar de Santa Maria. I, al mateix any, ja s'anomena l'altar de dins o l'altar de dintre. Dos espais que apareixeran doncs amb sengles paraments diferenciats: des de les IIII cortines barrades de groc i vermell per l'altar de fora e de dins als eixugamans de dintre i els de fora (i que en un altre document veiem descrits com els eixugadors de les mans de les dites dones, i els eixugadors de les mans per als preveres). Més enllà de la constatació d'un altar, que l'inventari especifica com a nostre ${ }^{40}$, el que és significatiu és l'ús conscient, funcional de les peces -des de les tovalloles al pal·lis- que ajuden a precisar i a marcar els "dos espais", el fora i el dins, o la reclusió i separació. Com senyala Columba Steward analitzant l'espai monàstic, la separació no només era una quiestió d'autonomia territorial, sinó també de comportament i de rutina diària. I conseqüentment hi ha tot una gestió dels objectes, de les imatges, que són les que realment aporten i donen la "frontera". Imatges concretes, etiquetades doncs amb el de fora o amb el de dins o nostro altar, en una rutina diària d'oració i activitat que col·loca les germanes en un temps i en un espai.

\section{ELS LLIBRES}

Hem deixat per al final la descripció i comentari dels llibres referenciats als inventaris de sagristia perquè esdevé per ell mateix un capítol especialment significatiu, que permet analitzar aspectes de la cultura escrita femenina, tant pel que fa a la presència del llibre en el convent, la seva disposició en l'espai, com als usos i pràctiques de lectura de la comunitat de les germanes ${ }^{41}$, que també pot ajudar a entendre els processos d'alfabetització femenina de la comunitat de germanes. D'altra banda, cal pensar que la sagristia fou, en general, en l'espai monàstic, el lloc on es conservaren des d'un començament els llibres, sota control del sagristà o sagristana, i no del bibliotecari42; i no serà fins més tard, darrers decennis del segle XV, quan es configuren les grans

40 L'arxiver Sebastià Roger ens dóna compte d'un altar del capítol, cuidat per una monja capitolera que s'encarregaria, en el ritual de confirmació de l'abadessa i la seva presa de possessió, de parar-lo i cobrir-lo de catifes, de situar-hi davant una catifa molt llarga amb dos o tres coixins de seda, vigilant que l'espai faci bona olor i hi hagi llums. També segons l'arxiver, l'elecció de l'abadessa i les vesticions d'hàbit es feia "abans de Trento", a la capella del cor. I fa referència a l'altar del cor, cuidat per la sagristana. En el quadre esmentat es referencien els altars al cor i la capella del cor -als peus de l'església-i a la sala del capítol.

${ }^{41}$ Una aproximació recent a l'univers de la cultura escrita en l'espai monàstic a B. Garí, What did Catalan Nuns Read?

${ }^{42}$ K.W. Humphreys, Les bibliothèques des ordres mendiants, p. 130. 
sales de les biblioteques monàstiques i conventuals ${ }^{43} \mathrm{i}$ comença a perfilar-se la figura de la bibliotecària ${ }^{44}$. La sagristana tindrà cura, en bona part dels contextos monàstics, dels llibres, juntament amb els ornaments litúrgics, joies i altres objectes de valor, i en general d'altres aspectes relacionats amb la litúrgia (compra de lluminària o ciris, candeles i brandons, teles per a paraments i vestimentes litúrgiques) ${ }^{45}$.

Aquests llibres apareixen, a l'inici de la nostra cronologia, a l'església (en l'església) com d'altres que es troben a l'armari de les cantós. A partir del 1406, l'enumeració dels llibres es farà de manera diferent: d'una banda, sota l'epígraf en l'església s'ubicaran la majoria de llibres que ja havíem retrobat en l'anterior document; l'armari de les cantós esdevindrà els dos armaris del faristol de les cantores; i apareix un nou epígraf on es diu que Aquestas són les coses qui són defora en la sgléya o Aquestas són las cosas qui són de fora en la sagristia, on hi hauran també llibres ${ }^{46}$. A partir de 1437, únicament es conserva la diferenciació entre els llibres que es troben als armaris del faristol de les cantores i els llibres de l'església. En relació a aquestes diferents ubicacions, podem pensar que els nostres inventaris, almenys fins el 1437, precisen l'existència d'uns llibres, la majoria, que són béns comunals sota l'administració de la sagristana; mentre que l'altra inclouria els còdexs adscrits als altars o beneficis de l'església ${ }^{47}$, però que tanmateix són controlats per ella ja que els inclou en el memorial ${ }^{48}$. Una situació semblant sembla derivar-se de la interpretació que fa Pedro Càtedra de l'inventari de convent de l'abadia cistercenca de San Clemente de Toledo -fruit d'una visita prescriptiva en nom del Papa per part del degà de la ciutat- de l'any 1331. Efectivament, els llibres, controlats en aquest cas per la capíscola o mestra de capella, se situen a l'espai pròpiament

43 Anne Prache esmenta les grans sales de les biblioteques dominicanes italianes i els exemples, més modestos en general, de les abadies cistercenques franceses: Bâtiments et décor, p. 354 .

${ }^{44}$ Per exemple, a les Constitucions del monestir de Santa Margarida de Palma, datades entre la fi del segle XV i els primers anys del XVI. Esmentat per B. Garí, What did Catalan Nuns Read?

45 Pedro Cátedra esmenta també que en alguns monestirs d'aquests llibres se n'ocupa més específicament la monja o monjo responsable de dirigir les activitats del cor (capiscola, capiscol). P. Cátedra, Lectura femenina en el claustro, p. 12.

46 Per exemple, a l'inventari de 1419 trobem, a l'armari del faristol de les cantores: un llibre de Sant Bernat, un de Santa Margarida i quatre "que servexen a les dones quan són a la mort"; i a defora l'església: dos Lleccionaris grans, vuit missals, nou saltiris, quatre santorals, dos locutus, quatre aspiciens, tres ordinaris, un llibre de vicis i virtuts, un llibre de Santa Paula.

47 Seguim M. Torras, El llibre a les esglésies i monestirs.

48 Als inventaris generals de convent, quan es parla del que controla la sagristana es diu també: el "que hi ha fora, a l'església" // "el que té la sagristana (AMSBM/MSCB, Inventaris, Plec 813, núm. 16, 1358); "fore en l'esgleya" // "té la sagristia" (AMSBM/MSCB, Inventaris, Plec 813, núm. 17, 1366). 
de l'església, als laterals de l'altar, per servir a l'ofici de la missa; d'altres s'ubiquen al cor, destinats als oficis de la litúrgia de les hores canòniques ${ }^{49}$.

$\mathrm{Si}$ enumerem el primer gruix de llibres que apareix al primer inventari de sagristia del 1389 tenim: tres capitolers, nou missals de cant, quatre santorals, dos locutus, dos aspiciens, dos llibres de cant, dos lliçoners, nou saltiris (cinc d'ells fermats amb cadenes), dos flos sanctorum, un llibre dels sants pares, un llibre de Ricard, dos ordinaris, tres llibres d'oficis de morts, un llibre de Santa Paula, un llibre anomenat datari, un llibre de les dones difuntes, un llibre dit monçonequer, dos llibres en què aprenen les infantes, una Bíblia, una regla, un Dominus dixit, un llibre dit canòniques, un llibre que serveix per la Quaresma. I es detallen els llibres que es conserven a l'armari de les cantós: tres llibres a obs de les dones quan són al trànsit, un llibre de Santa Margarida, un llibre de la prosa dels morts, i un llibre de la Pàssia. Al tancament de la nostra cronologia, a la dècada de 1460, consten: dos leccionaris, nou missals, nou saltiris -entre nous i vells-, quatre santorals, quatre locutus, quatre aspiciens, dos ordinaris, un llibre de vicis i virtuts, un llibre de Santa Paula, dos libres prims en què ligen les fadrines, un llibre vermell de les lissons de Sent Francesch e Santa Clara, un llibre dels versets, un llibre dels Sants Pares, un llibre en lo qual scriuen les monges mortes, dos capítules, un breviari, un diürnal, un llibre de cant en què aprenen les fadrines, un Flos Sanctorum, un llibre dels àngels, una regla, un cuern (quadern) de Sant Antoni, un Dominus dixit i un breviari. I a l'armariet del faristol de les cantores, tan sols resta el datari i apareix un llibre del confessor.

Sobre els tipus de llibres, advertim, en primer lloc, la presència de còdexs, en què aprenen les infantes o fadrines, fet que pot demostrar l'existència de nenes petites al monestir que hi rebien una educació encaminada en principi, tot i que no solament, a la professió religiosa. En aquest sentit, es fa evident la funció educadora de l'espai monàstic, des dels primers temps del monacat ${ }^{50}$. Si bé en molts dels casos aquesta funció no deixaria de ser una instrucció, centrada més en un ensenyament de caire religiós (per a la liturgia i el res) i de caire moralitzant, la realitat del monacat és prou rica i complexa com per no projectar-hi els paràmetres fixes i uniformitzadors que l'església pretengué imposar a partir del Concili de Trento ${ }^{51}$. En qualsevol cas, les regles clarisses esmenten la presència de la mestra de novícies, que iniciarà la monja,

49 P. Cátedra, Lectura femenina en el claustro, pp. 12-14.

50 María Echániz documenta, al Sancti Spiritus de Salamanca, l'existència de nenes al monestir, en alguns casos identificades com a "mozas de coro" (que podríem assimilar a les escolanes, presents a la nostra documentació), per tant que no han pres l'hàbit ni tampoc han professat, i que són educades en part per a la professió religiosa. M. Echániz, El monasterio de Sancti Spiritu de Salamanca, p. 60.

51 M.M. Graña, ¿Leer con el alma y escribir con el cuerpo?, p. 403. 
la novícia, en les disciplines regulars, en una relació en què se situaria aquesta tipologia de llibres $^{52}$. Els casos esmentats ens parlen, a l'inici de la nostra cronologia, de II llibres prims, sense altra característica que faci avançar en la seva tipologia, o bé "llibres de cant" -com I libre de cant en què aprenen les fadrines, present a partir de l'inventari de 1421. Podem pensar, pel que fa als llibres prims, en quaderns, taules que contenien els alfabets o abecedaris i que servien com a primer llibre o suport didàctic per a ensenyar a llegir a nens i nenes. El llibre de cant podria tractar-se d'un Salteri, un llibre o selecció de salms, que se sap que era també usat com a sil·labari i com a llibre de lectura per a l'exercitació i per aprendre a llegir i/o escriure ${ }^{53}$. Aquest aprenentatge de la lectura a través dels llibres per part de les "fadrines", escolanes o també les novícies, $\mathrm{s}$ 'ha documentat igualment en el monestir germà de Pedralbes ${ }^{54}$.

Són majoria, en el catàleg, els llibres de caràcter litúrgic, necessaris a la celebració de l'ofici i de les hores (missals, oficiers/oficiaris, ordinaris, capitolers, epistolers, santorals, saltiris, breviaris, ordinaris, diürnals ${ }^{55}$, leccionaris), al costat dels llibres de cant, fonamentals també per a una bona part dels oficis i de les misses ${ }^{56}$; si pensem, a més, que varen ser els franciscans els que van difondre arreu d'Europa un nou repertori musical per a la missa que seguia el ritual romà, podem incidir encara en el lloc important d'aquests llibres corals en la litúrgia i les pregàries del monestir.

S'esmenten alguns llibres hagiogràfics, de lectures de vides de sants (el Flos Sanctorum, translació de la Llegenda Àurea; o d'altres dedicats a sants concrets: de Santa Paula, de Santa Margarida -llibre vermell de Santa Margarida-, de Sant Bernat, de Sant Francesc i Santa Clara, i podem pensar també aquí en el quadern de Sant Antoni). Destaca igualment la presència d'una lectura de caire moralitzant, Llibre de vicis $i$ virtuts, que és probablement la traslació catalana del Somme le Roi del dominic Laurent d'Orleans o du Bois (mort vers 1300) ${ }^{57}$, força corrent en biblioteques laiques, i esmentat

52 Un dels primers oficis o càrrecs documentats al monestir de Sant Antoni justament és aquest: Maria, vídua de Berenguer de Vic, a través del seu testament (1279) determina ser sepultada al monestir i deixa a sor Caterina, "magistre" de la seva filla Guillema, monja, un sou. AMSBM/MSCB, Col-lecció de pergamins, núm. 691.

${ }_{53}$ M.E. Varela Rodríguez, Aprender a escribir, aprender a leer.

${ }^{54}$ A. Castellano, Pedralbes a l'Edat Mitjana, p. 325: "IIII libres qui foren dels Templés en què aprenen les nines".

55 Alexandre Olivar referencia un diünal escrit per a la comunitat a la primera meitat del segle XIV.A. Olivar, Catàleg dels manuscrits. Un diürnal apareix per primera vegada a l'inventari de 1454: "Ítem, un Diornal qui stà farmat a la porta del torn".

56 Seguint Anna Castellano, sembla ser que hauria existit un ofici específic per a les monges de Santa Clara, que tenia la particularitat de ser cantat: A. Castellano, Pedralbes a l'Edat Mitjana, pp. 318-319.

57 J.N. Hillgarth, Readers and Books in Majorca. 
també al primer inventari general de Santa Maria de Pedralbes del 1364, que proporcionaria el primer perfil de la seva biblioteca monàstica ${ }^{58}$. S'esmenta també, per primera vegada a l'inventari de 1461 (per tant ja tancant la cronologia analitzada), el Libra dels Àngells, probablement l'obra de Francesc Eiximenis, un tractat d'angelogia destinat a estendre el culte i el coneixement dels àngels i a divulgar punts fonamentals de la moral i de la fe cristianes, $i$ que es va convertir en l'obra del franciscà més llegida i d'èxit més fulminant des de la seva publicació el $1392^{59}$.

Com ha constatat també pel cas de Pedralbes la historiadora Anna Castellano, són pocs els exemples inclosos en aquesta categoria d'obres de caràcter espiritual i devocional -enfront dels predominants llibres litúrgics per a l'església i el cor. La seva presència ens acostaria a d'altres modalitats de lectura, comunitària, a taula o al refetor ${ }^{60}$. Certament, el fet que ens trobem davant d'un inventari de sagristia pot esbiaixar el perfil de les lectures inventariades; i, de la mateixa manera, se'ns escapen probablement també 1libres i lectures d'ús particular, personal, que no són d'ús comú -adquirides per monestir o donades a la comunitat-, i que no s'utilitzen en les diverses pràctiques, litúrgiques o no, col·lectives.

En menor grau, són presents textos bíblics i escripturístics, com ara una Bíblia, un Llibre dels Sants Pares o un Llibre verd dels Evangelis. Destaquen també alguns llibres vinculats al rituals o a dates particulars del calendari litúrgic, com ara el llibre de la Pàssia -narració evangèlica de la passió i mort de Jesucrist, que es recita o canta en les misses del dia de Rams i del Dimarts, Dimecres i Dijous Sant $-{ }^{61} \mathrm{o}$ el llibre del Mandat -cerimònia en què es commemora el lavatori dels peus dels apòstols per Jesucrist, i sermó que es fa en aquesta cerimònia. Els inventaris detallen l'existència de llibres de la Regla, que al 1461 són dos exemplars ${ }^{62}$; i, des del principi, llibres en què s'escriuen les germanes mortes, llibre de les dones mortes, i llibre d'ofici de morts, de la prosa dels morts o encara a obs de les dones quan són al trànsit, que donarien compte d'altres rituals extraordinaris, com el de difunts; o també un llibre

58 A. Castellano precisa l'existència, en aquest inventari, d'una obra sobre Sant Francesc (Libre de miracles de Sent Francesch) i una altra sobre Santa Magdalena (Libre de Santa Maria Macdalena). A. Castellano, Pedralbes a l'Edat Mitjana, p. 330.

59 Manuscrit present també al monestir de Sant Pere de les Puel·les, segons les darreres recerques de J. de Puig i Oliver Catàleg dels manuscrits de les obres de Francesc Eiximenis.

60 En el primer inventari general, de convent, que conserva el fons de Santa Clara de Barcelona, de l'any 1337-1338, es parla del "Breviari que està a la capella i qui es llegeix a taula", i del llibre de Santa Magdalena "que es llegeix a taula". AMSBM/AMSCB, Inventaris, núm. $813(21-22)$.

61 DCVB.

${ }^{62}$ Es conserva un exemplar de Regla de Santa Clara, en català, a la Biblioteca de Catalunya ms. 3723. Jesús Alturo, El llibre manuscrit a Catalunya, el situa al segle XV. 
dels aniversaris i un llibre de les absolucions. Llibres que, en definitiva, se situarien també a mig camí de la litúrgia i de les pràctiques internes -rituals i costumaris del monestir-, com també del registre o memòria de l'arxiu.

Alguns títols apareixen al principi de la cronologia, com el llibre identificat com de Ricard (possiblement alguna obra del teòleg i místic Ricard de Sant Víctor) que s'esmenta tan sols el 1389. Per contra és ben present encara al 1461 el llibre anomenat Datari, en què lligen la lluna (segons se'ns especifica el $1421^{63}$ ) i que podria tractar-se d'un compter o calendari ${ }^{64}$. Hi ha únicament una referència d'un Llibre d'Hores, a l'inventari de l'any $1421^{65}$. Enigmàtic el títol del llibre apellat Monçonequer (1389), Monsonaguer $(1419)^{66}$.

El locutus i l'aspiciens, serien llibres de cant, responsoris ${ }^{67}$; mentre que el Dominus dixit al·ludiria al salm de vespres també cantat. L'Exultet in Angelica, que apareix en dos dels inventaris $(1406,1421)$ serà el pregó pasqual, un dels himnes més antics de la tradició liturgica romana, cantat la nit de Pasqua. Algunes descripcions, com la d'algun oficier (Oficier per entonar les cantós, Oficier per cantar) ens remeten de nou a aquesta presència de la música que acompanya en aquest cas el text dels oficis divins, com també la instrucció/aprenentatge de les fadrines (1 libre de cant en què aprenen les fradines). Fet que completaria, en definitiva, un ric repertori de cant ${ }^{68}$.

Les descripcions dels còdexs a l'inventari deixen entreveure altres espais del llibre que indiquen la seva relativa dispersió dins del monestir, més enllà d'aquest entorn de la sagristia, el cor de les monges amb el faristol o als altars-beneficis de l'església: al capítol -un breviari que apareix ja el 1389 i es manté el 1461; a la porta del torn -un diürnal (1461); al refetor -un Flos

\footnotetext{
${ }^{63}$ A l'inventari de convent de 1366 s'especifica més: "I Datari en què·s diu la luna a Pasqua" (AMSBM/AMSCB, Inventaris, Plec 813, núm. 17).

${ }^{64}$ Miquel Torras, a la seu de Manresa, troba un Datari i en fa aquesta interpretació. M. Torras, El llibre a les esglésies i monestirs de Manresa al segle XIV, p. 10. El DCBV ens remet a un Llibre de dates, on es consignaven els fets d'una comunitat, d'un poble.

${ }^{65}$ Es conserva a l'Arxiu Històric de la Ciutat de Barcelona (ms. A 398) un Llibre d'Hores que hauria pertangut a la comunitat de Sant Antoni i Santa Clara de Barcelona, propietat primer d'una família de mercaders, els Llobera, amb miniatures atribuïdes a Bernat Martorell. Algunes de les anotacions del còdex el situen cap a la dècada del 1430: J. Planas, Bernat Martorell miniaturista.

66 "Monsonaguer" (en altres variants mençoneguer, monçoneguer), terme que, segons el DCVB, vol dir "mentider".

${ }^{67}$ Cantus: A Database for Latin Ecclesiatical Chant, Indices of chants in selected manuscripts and early printed sources of liturgical Office (http://cantusdatabase.org/).

${ }^{68}$ El 1410,per exemple, si comptem la designació "llibres de cant" (nou llibres), més els tres locutus i els dos aspiciens, conformen un conjunt de catorce llibres. quatre llibres d'aspiciens són ressenyats a l'inventari de l'abadia cistercenca femenina de San Clemente de Toledo, de l'any 1331, segons l'estudi de P. Cátedra, Lectura femenina en el claustro, pp. 12-22.
} 
Sanctorum-, un llibre verd dels Evangelis, una Bíblia, dues regles, un Dominus dixit (1421); al claustre -un breviari (1389). S'aprecien finalment algunes disposicions del llibre particulars, que al-ludeixen al concepte de "llibres encadenats", d'acord amb un costum medieval ben estès: el diürnal encadenat a la porta del torn (1461), el llibre de Santa Paula encadenat o fermat al cap de l'altar (1410), un breviari que està fermat al faristol de les cantores (1410) o els cinc saltiris fermats amb cadenes (1389). Al darrere d'aquest terme apareix per tant una disposició particular -que s'associaria, com s'ha constatat en d'altres entorns tant monàstics com també universitaris, a un element del mobiliari: el pupitre inclinat o l'armari-llibreria-, i una idea de facilitar l'accés a uns llibres que serveixen per a tots, ad utilitatem commune o in loco commu$n e^{69}$. En aquest sentit s'expressava el mateix Ramon Llull en el seu testament quan dóna instruccions perquè els llibres siguin conservats, encadenats, als armaris-llibreria de les esglésies, i afavorir així la seva accessibilitat a tothom que hi estigui interessat ${ }^{70}$.

Els inventaris ens proporcionen finalment, en aquest punt de la cultura escrita i l'univers textual i codicològic de les germanes, d'altres aspectes més formals dels llibres. Ja el 1389 apareix que el capitoler que serveix a les festes té una coberta obrada de seda (i al 1419, n'apareix una altra, de drap d'or). El 1461, es referencien dues cobertes de drap de lli per lo capitoler nostro (1461). L'inventari de 1410 ens precisa que unes cobertes blanques de drap de lli són per les Lliçons o lleccionari -llibre de cor que conté les matines-, pel Flos Sanctorum i pel datari. Descobrim també que hi havia dues cobertes obrades pel missal major que està defora. El 1433 es fa una nova coberta pel datari, de domasquí negre. I encara el 1437 es referencien dues cobertes per a un capitoler: una vermella de brocat d'or forrat de sendat amb passamà d'or $\mathrm{i}$ seda; l'altra blanca de lli brodada negra. En una funcionalitat similar es trobarien les davanteres, com les dues de seda que serveixen al capitoler: una violada amb botons d'or daurats amb dos braços d'argent daurats amb senyal de Cruillles; l'altra és de canons i amb botons d'or i amb ganxets d'argent daurat. A les noves cobertes, se li han afegit al capitoler altres elements relacionats amb el seu ús i lectura: uns giradors ${ }^{71}$ amb un botó gros de perles al cap, amb un collet vermell amb nou botons de perles blanques al girador, amb dos tancadors de parxe, els quals tenen els caps d'argent daurants; i en els caps dels tancadors hi ha dos cordons d'or i de seda amb vuit botons de perles petites. Veiem en tot cas l'atenció i cura que se li ha dedicat a aquest llibre major, el

${ }^{69}$ Són els termes que retroba Jean Vezin en alguns catàlegs de biblioteques de l'època, com el de la Sorbona, el 1338: J. Vezin, Le mobilier des bibliothèques, pp. 368-369

70 A. Solé, La transmissió de l'obra de Ramon Llull, p. 52.

71 DCBV: Cinta posada en un llibre per a girar-ne fàcilment les fulles i servir de senyal. 
capitoler o capitulari ${ }^{72}$. En l'inventari del 1410, per exemple, es compten un total de sis capitolers, entre els quals el que serveix a les festes solemnes, $i$ un de vermell amb senyals de Sant Anthoni.

Certament, ens trobem amb un tipus de còdexs, la descripció dels quals, especialment en les seves cobertes i enquadernacions, fan pensar en rics exemplars. Si bé alguns d'ells foren escrits i confeccionats explícitament per a les menoretes de Santa Clara de Barcelona, com el diürnal esmentat, d'altres còdexs pogueren arribar per llegats testamentaris o com a dotacions d'altars-beneficis. És el cas, molt probablement, del missal referenciat com de "na Blanca" esmentat més amunt, al costat d'altres objectes que completarien un conjunt per a l'altar. En la relació de beneficis eclesiàstics de l'església del monestir, consta efectivament el benefici de Nostra Senyora a l'altar de Nostra Senyora instituït per Blanca, molt probablement Blanca de Sicília (1330-1370), comtessa consort d'Empúries ${ }^{73}$.

Hauríem de pensar, en definitiva, que pogueren entrar per aquesta via (regals, llegats testamentaris, dotacions altars) no solament còdexs ricament ornats i coberts, sinó també altres tipus de lectures, individuals o comunitàries, fora de l'àmbit estrictament litúrgic o paralitúrgic. I, des d'aquí, es pot perfilar una xarxa de relacions, de lectures i pietat compartides, que acosten les dones laiques, que poden ser al mateix temps protectores o mecenes de la comunitat, a les germanes ${ }^{74}$.

\section{CONCLUSIONS}

Hem vist com en aquesta relació de béns inventariats pren significativament importància la consignació minuciosa del temps (temps litúrgic, devocional) i l'espai (el dins i fora) que acompanya les peces. És aquesta

\footnotetext{
${ }^{72}$ Possiblement cal pensar en els col-lectaris-capitularis presents en entorns similiars com la catedral de Vic o el monestir de Poblet, on Agustí Altisent ho retroba sota el terme "col·lectani" i que comprendria: les oracions de la missa, els breus passatges bíblics resats a l'ofici coral anomenats "capítules", les pregàries per a l'administració dels sagraments i altres diverses oracions i benediccions, i possiblement precedit del calendari de les festes litúgirques de l'any. A Altisent, La biblioteca de Poblet al llarg del temps, p. 3.

${ }_{73}^{73}$ Així consta en els registres episcopals: ADB, Registre Communium (1375-1378), núm. 38.

${ }^{74}$ Sabem que la comunitat va acollir el dipòsit o comanda dels béns de l'infanta Joana, filla de Pere III, casada amb Joan I d'Empúries, i morta el 1384. Concretament eren dos cofres amb robes, draps de la capella i objectes de culte i alguns llibres.La comanda, que la dita Joana lliurà a l'abadessa del monestir, fou feta el 7 de noviembre de 1360. El 13 de juliol de 1363 la infanta ordenà a a l'abadessa que ho donés tot al seu cambrer que en féu àpoca, probablement en previsió del seu matrimoni amb el rei de Castella, que no es portaria finalment a terme. Vegeu M.M. Costa, Joana d'Aragó, p. 145. La Constança, "reina de Sicília", que va visitar el monestir el 1360 i 1376, tal com consta en el Llibre de coses dignes de memòria, iniciat amb Sebastià Roger el 1599, seria molt probablement la seva germana: AMSBM/MSCB, Manuals, núm. 742.
} 
perspectiva d'estudi i d'interpretació dels inventaris de sagristia, que dóna a les peces inventariades un context performàtic en què la peça es posa en relació, s'usa i es pren, la que creiem que pren força i pot tenir continuïtat. La font que proporciona l'inventari de sagristia pot ajudar en els estudis que han treballat el concepte de "performance devocional", que acull essencialment pràctiques -gestos, veneració d'objectes, rituals integrats en la quotidianitat de la comunitat ...- i, com hem vist, espais i relacions ${ }^{75}$. Un element que es podria complementar amb d'altres fonts documentals, com són els costumaris, els cerimonials i les ordinacions, on podem trobar també consignacions

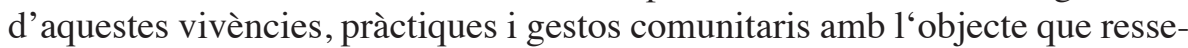
nya l'inventari. Així per exemple, en els rituals de nomenament i benedicció de l'abadessa, veiem alguna de les peces que han pogut ser registrats en els inventaris - des de la crossa de l'abadessa a les claus de l'abadia o el parament de l'altar del cor durant la cerimònia ${ }^{76}$. I, encara, un text de caràcter més normatiu com són les ordinacions de l'abadessa Agnès sobre la celebració dels oficis divins que han dur a terme els capellans i sacerdots beneficiats de l'església del monestir, deixaria traspuar tot el ritual i comportament dels beneficiats en relació a la seva vestimenta litúrgica i al parament litúrgic dels seus altars o capellanies ${ }^{77}$.

Certament, la dimensió material dels objectes inventariats, en la seva quantitat i qualitat, permetria avançar en l'anàlisi que relaciona l'inventari de sagristia amb el patrimoni econòmic i cultural de la comunitat, com també amb el seu lloc en la topografia religiosa de la ciutat de Barcelona. Igualment fóra interessant, en aquesta perspectiva, connectar la presència d'alguns dels objectes amb el seu origen, herència i/o dot de les germanes, llegats i donacions de tota la xarxa de feligresos -que al seu torn mantenen clars vincles de parentiu amb les germanes- i continuar apostant pel lligam evident amb el cercle de reines i infantes, promotores i protectores de les menoretes -com acabem de comprovar.

Finalment, com ha remarcat Pedro Cátedra, l'estudi i l'anàlisi dels inventaris pot substituir i esmenar la pobresa o escassedat de les disposicions reglamentàries pròpies que, a l'interior de l'orde clarissa, parlen de la pràctica

\footnotetext{
75 Una bona síntesi i aproximació a aquesta perpectiva a: B. Garí, The Sacred Space of Meditation.

76 Cerimonial d'abadesses (1594), AMSBM/MSCB, Manuals, núm. 633, si bé ja es tracta d'un cerimonial de l'etapa benedictina de la comunitat.

77 Ordinacions i constitucions de l'abadessa del monestir de Sant Antoni de Barcelona, de l'orde de Santa Clara, de l'any 1260, sobre la celebració dels oficis divins que han de dur a terme els capellans $i$ sacerdots beneficiats a l'església del monestir, AMSBM/MSCB, "Llibre d'actes capitulars", núm. 741, ff. 2-3: Biblioteca virtual d'investigació Duoda http://www. ub.edu/duoda/bvid/text.php?doc=Duoda:text:2012.03.0008.
} 
de la lectura i ajudarien a perfilar la biblioteca monàstica ${ }^{78}$. En el cas específic dels inventaris de sagristia, que com hem vist són tancament de la gestió d'aquest càrrec o ofici a l'interior de la comunitat, disposaríem a més d'una font no tan esbiaixada com ocorre en bona part dels inventaris de comunitats femenines que conservem i que són resultat d'una visita d'inspecció i control per part d'una autoritat externa ${ }^{79}$. És per tant des d'aquesta argumentació que els inventaris de sagristia poden esdevenir una font de primer ordre per a l'estudi de la cultura escrita als monestirs femenins.

A les darreres dècades del segle XIV i mitjan segle XV -marc cronològic del nostre estudi-, el monestir de Sant Antoni i Santa Clara es troba ben inserit a la trama urbana barcelonina, ocupant l'espai més oriental i marítim, al costat de la Muralla de la Marina, construïda entre 1358 i 1362 -i que, de fet, inclou el monestir dins el recinte murat de la ciutat, fins aleshores extramurs. En la topografia monàstica de Barcelona s'ha fundat un altre monestir de l'orde de Santa Clara, el de Santa Maria de Pedralbes (1326); fundació reial que ha comptat amb una primera dotació de germanes procedents del vell monestir de Santa Clara que s'hauria originat d'una prèvia associació de dones penitents, de perfils informals, sense perdre de vista les connexions -ja sigui per vinguda d'algunes monges italianes com per la peregrinació d'algunes de les penitents barcelonines-amb les comunitats de damianites que sorgien a Itàlia, i sota l'impacte del model de Clara d'Assís ${ }^{80}$.

Deixem la comunitat barcelonina, en la data del darrer inventari, l'any 1461, preparada per al seguit de reformes monàstiques que tindran com a colofó la reforma del monestirs femenins empesa pels Reis Catòlics (1493-1495). En aquest procés, la veurem defensar una certa especificitat fruit del seu origen antic -en moments en què tot just es configurava la família clarissa dins de la família franciscana, es debatien temes essencials com la cura monialum per part dels framenors o se succeïen diverses normatives clarisses. De fet, el nostre monestir iniciaria la centúria del 1500 amb un

${ }^{78}$ P. Cátedra, Lectura femenina en el claustro, p. 22.

79 Ibidem, p. 10.

${ }^{80}$ Manquen estudis monogràfics que avancin el coneixement d' aquesta comunitat. A la meva tesi doctoral (N. Jornet, Sant Antoni i Santa Clara de Barcelona) vaig analitzar la fundació de la comunitat a la dècada del 1230 fins al 1326, data en què es funda a la ciutat de Barcelona Santa Maria de Pedralbes. La revisió bibliogràfica demostrà l'escàs tractament de la comunitat, més enllà de la seva inclusió en les cròniques i històries de l'orde. D'altra banda, el treball, paral·lel, d'organització de l'arxiu monàstic - amb la definició de les principals tipologies documentals, la història del tractament arxivístic, de l'arxiu i de les arxiveres de la comunitat-, que es va incloure també a la tesi, va permetre posar al descobert un fons monàstic d'excepcional riquesa, poc conegut i explotat encara. El canvi a la família benedictina, primer, la destrucció del monestir durant la Guerra de Successió del 1714, després, i encara el pes significatiu en l'imaginari social del convent de Pedralbes, han fet en certa manera que hagi estat fins fa ben poc una comunitat poc referenciada en la topografia monàstica catalana. 
gir ben radical en la seva història, la mutació cap a la família benedictina (1513). Deixem, encara, en aquestes dates dels inventaris, la vella comunitat barcelonina intervenint activament en la memòria comunitària ${ }^{81}$, donant significat a la llegenda fundacional, ben arrelada a la tradició popular, a través del culte a les dues fundadores, Agnès i Clara, tingudes per santes. De l'any 1460, sota l'abadiat d'Elionor de Rajadell (que, recordem-ho, havia estat sagristana), és el primer ritual de translació dels dos cossos sants des de les sepultures del terra a l'interior de l'església del monestir. Això, és ja, però, una llarga història ${ }^{82}$.

\section{BIBLIOGRAFIA CITADA}

Altisent, Agustí, La biblioteca de Poblet al llarg del temps. Extractes de la seva Història de Poblet, http://www-poblet.cat/pfw-files/ema/Content/ arxius/La_Biblioteca_de_Poblet.pdf. [consulta:30/09/2013].pp. 1-35.

Alturo, Jesús, El llibre manuscrit a Catalunya: orígens $i$ esplendor, Barcelona, Generalitat de Catalunya, 2000.

Cantino Wataghin, Gisella, Concluding Remarks, dins Dey, H.; Fentress, E. (eds.), Western monasticism ante litteram. The spaces of monastic observance in late antiquity and the early middle ages, Turnhout, Brepols, 2011, pp. 355-377.

Cantus: A Database for Latin Ecclesiatical Chant, Indices of chants in selected manuscripts and early printed sources of liturgical Office: http:// cantusdatabase.org/ [consulta: 30/09/2013].

Castellano, Anna, Pedralbes a l'Edat Mitjana. Història d'un monestir femení, Barcelona, Publicacions de l'Abadia de Montserrat, 1998. (Biblioteca Abat Oliva; 198).

Cátedra, Pedro, Lectura femenina en el claustro (España, siglos XIV-XVI), dins Courcelles, Dominique de; Val Julián, Carmen (eds.), Des femmes et des livres. France et Espagnes, XIVe-XVIIIe siècle, París, École des Chartes, 1999, pp. 7-53.

Costa, Maria-Mercè, Joana d'Aragó (1344-1384), "Estudis d'Història Medieval" 6 (1973), pp. 137-209.

\footnotetext{
${ }^{81}$ Com diuen les editores del llibre col-lectiu, G. Zarri; N. Baranda, Memoria e communità femminile. Spagna e Italia, secc XV-XVII, el llarg fil de la memòria conventual els ha permès explorar de manera conjunta com es construeixen identitats personals i colllectives, i com es transmet una geneologia femenina, pròpia.

82 Tracto tot aquest aspecte del culte de les santes fundadores i els diversos rituals de translació, així com el procés de beatificació i confirmació del seu culte immemorial a: N. Jornet, $E l$ monestir de Sant Antoni de Barcelona.
} 
Diccionari català-valencià-balear. Alcover-Moll (DCVB) http://dcvb.iecat. net/ [consulta: 30/09/2013].

Echániz, María, El monasterio de Sancti Spiritus de Salamanca. Un espacio monástico de mujeres de la Orden Militar de Santiago (siglos XIIIXV), "Studia Historica. Historia Medieval" 9 (1991), pp. 43-66.

García Valverde, María Luisa, Legislación archivística monacal durante el siglo XVI, dins Tomás Quesada Quesada. Homenaje, Granada, Universidad de Granada - Facultad de Filosofía y Letras, 1998, pp. 719-739.

Garí, Blanca, The Sacred Space of Meditation. Nunneries and Devotional Performance in the Territories of the Crown of Aragon (14th-15th centuries), "The Journal of Medieval Monastic Studies" 4 (en premsa).

Garí, Blanca, What did Catalan Nuns Read? Women's Literacy in the Monasteries of Catalonia, Majorca and Valencia, dins Blanton, Virginia; O'Mara, Veronica; Stoop, Patricia, Nuns' Literacies in Medieval Europe: The Antwerp Dialogue, Belgium, Universiteit Antwerpen (en curs de publicació).

Graña, María del Mar, ¿Leer con el alma y escribir con el cuerpo?: reflexiones sobre mujeres y cultura escrita, en Castillo, Antonio (coord.), Historia de la cultura escrita. Del Próximo Oriente antiguo a la sociedad informatizada, Gijón, Trea, 2002, pp 385-452.

Hamburger, Jeffrey F., Nuns as artists. The visual culture of medieval convent, California, University of California Press, 1997.

Humphreys, Kenneth William, Les bibliothèques des ordres mendiants, dins Histoire des bibliothèques françaises. Les bibliothèques médiévales du VIe siècle à 1530, París, Ed. Cercle de la Librairie, 1985, pp. 125-145.

Jornet Benito, Núria, El monestir de Sant Antoni de Barcelona: l'origen $i$ l'assentament del primer monestir de clarisses a Catalunya, Barcelona, Publicacions de l'Abadia de Montserrat, 2007. (Scripta et documenta; 76).

Jornet Benito, Núria, Sant Antoni i Santa Clara de Barcelona: origen d'un monestir i configuració d'un arxiu monàstic, Barcelona, Universitat de Barcelona, 2005 (tesi doctoral). http://www.tdx.cat/handle/10803/119825.

Jornet Benito, Núria, Memoria, historia y archivo en el monasterio de Sant Antoni i Santa Clara de Barcelona, "Boletín de la ANABAD" 4 (2008), pp. 297-305.

Jornet Benito, Núria, Ordinacions i constitucions de l'abadessa del monestir de Sant Antoni de Barcelona, de l'orde de santa Clara, de l'any 1260, sobre la celebració dels oficis divins que han de dur a terme 
els capellans $i$ sacerdots beneficiats a l'església del monestir. Transcripció, traducció al català i al castellà modern, i estudi Biblioteca virtual d'investigació Duoda: http://www.ub.edu/duoda/bvid/text. php?doc=Duoda:text:2012.03.0008 [consulta: 27/02/2014].

Hillgarth, Jocelyn Nigel, Readers and Books in Majorca, 1229-1550, vol. I, París, CNRS, 1991.

Masnou i Pratdesaba, Josep M., Inventari de la sagristia de la Seu de Manresa (1452), "Miscel-lània litúrgica catalana" 15 (2007), pp. 305-316.

Olivar, Alexandre, Catàleg dels manuscrits de la biblioteca del monestir de Montserrat, Barcelona, Publicacions de l'Abadia de Montserrat, 1991.

Planas, Josefina, Bernat Martorell miniaturista: el Saltiri-Llibre d'Hores de l'Arxiu Històric de la Ciutat de Barcelona, dins Molina, Joan (ed.), Bernat Martorell i la tardor del gòtic català: el context artístic del retaule de Púbol, Girona, Museu d'Art de Girona, 2003, pp. 43-60.

Prache, Anne, Bâtiments et décor, dins Histoire des bibliothèques françaises. Les bibliothèques médiévales du VIe siècle à 1530, París, Éd. Cercle de la Librairie, 1985, pp. 351-366.

Puig i Oliver, Jaume de, Catàleg dels manuscrits de les obres de Francesc Eiximenis ofm, conservats en biblioteques públiques. Volum I: descripció dels manuscrits, Barcelona, Institut d'Estudis Catalans - Facultat de Teologia de Catalunya, 2012.

Rodríguez Parada, Concepción, Los catálogos e inventarios en la historia del libro y las bibliotecas, "BiD. Textos universitaris de biblioteconomia i documentació" 18 (2007) http://bid.ub.edu/18rodri3.htm [consulta: 30/09/2013].

Solé, Albert, La transmissió de l'obra de Ramon Llull, dins Ramon Llull: història, pensament i llegenda, Palma de Mallorca, Obra Social Fundació La Caixa, 2008, pp. 47-54.

Steward, Columba, Monastic space and time, dins Dey, Hendrik; Fentress, Elizabeth (eds.), Western monasticism ante litteram. The spaces of monastic observance in late antiquity and the early middle ages, Turnhout, Brepols, 2011, pp. 43-51.

Terés, Rosa, Violant de Bar: les inclinacions artístiques d'una reina francesa a la Corona d'Aragó, dins Terés, Rosa (coord.), Capitula facta et firmata. Inquietuds artístiques en el quatre-cents, Valls, Cossetània Edicions, 2009, pp. 9-69.

Torras, Miquel, El llibre a les esglésies i monestirs de Manresa al segle XIV, "Dovella" 102 (2009), pp. 5-13.

Varela Rodríguez, M. Elisa, Aprender a escribir, aprender a leer: lectoescritura femenina (siglos XIII-XV), dins González de la Peña, M. del Val, Mujer y cultura escrita. Del mito al siglo XXI, Gijón, Trea, pp. 59-74. 
Vezin, Jean, Le mobilier des bibliothèques, dins Histoire des bibliothèques françaises. Les bibliothèques médiévales du VIe siècle à 1530, París, Éd. Cercle de la Librairie, 1985, pp. 365-371.

Zarri, Gabriela; Baranda Leturia, Nieves, Memoria e comunità femminile. Spagna e Italia, sec. XV-XVII, Florència, Firenze University Press - UNED, 2011.

Fecha de recepción del artículo: noviembre 2013

Fecha de aceptación y versión final: mayo 2014 